\title{
Cooperative optimal configuration of electricity storage and heat storage based on particle swarm optimization
}

\author{
Te Cheng ${ }^{1}$, Fei Xu ${ }^{1}$, Ling Hao ${ }^{1, \square}$, Lei Chen ${ }^{1}$, Qun Chen ${ }^{2}$, and Yong Min ${ }^{1}$ \\ ${ }^{1}$ Department of Electrical Engineering, Tsinghua University, Beijing, China \\ ${ }^{2}$ School of Aerospace Engineering, Tsinghua University, Beijing, China
}

\begin{abstract}
During the heating season in my country's Three Norths, the operation mode of "using heat to determine electricity" for cogeneration units has made the "wind curtailment rate" high. Electricity storage and heat storage are both important ways to solve this problem. In order to determine the optimal power and capacity of heat storage and power storage devices, this paper proposes a two-layer optimization model that considers the economic benefits of the entire system and the life of the power storage device is affected by its operation. Comsidering the iterative life of the power storage device, the optimal solution for the power, capacity and location of the heat storage and power storage device is obtained by using the particle swarm algorithm. Finally, the actual data of the IEEE classic 33-node system verifies the effectiveness of the proposed method.
\end{abstract}

\section{Introduction}

Making full use of renewable energy such as wind power and photovoltaics is the basic strategy of my country's energy development ${ }^{[1]}$. For a long time, the State Grid Electric Power Company has provided comprehensive services for the access and consumption of renewable energy from grid planning, grid construction, dispatch operation and market transactions, which has enabled my country's renewable energy to achieve leapfrog development ${ }^{[2]}$. The installed capacity of wind power and photovoltaics ranks first in the world. With the rapid development of renewable energy, wind power and photovoltaics, due to their inherent randomness and volatility, make the consumption of wind power and photovoltaics increasingly serious, which obviously restricts the further development of renewable energy ${ }^{[3]}$. Especially in the heating season in my country's "Three Norths" area, in order to meet the heating demand, the cogeneration units work in the "fixed electricity by heat" mode, which significantly reduces the flexibility of the system, resulting in a large number of "abandonment of wind and energy ${ }^{[4] "}$.

At present, there have been many studies on new energy generation and consumption solutions. Literature [5] shows that adding heat storage devices in thermal power plants and effectively increasing the absorption capacity of new energy in the integrated energy system. The configuration of power storage devices is an effective means to improve the flexibility of the power system, and it will obviously also have a positive impact on the consumption of new energy in the system. Although multiple forms of energy storage improve the new energy consumption capacity of the integrated thermoelectric

*Corresponding author: haolg@foxmail.com system, it also increases the initial investment cost of the system. Therefore, how to optimize the distribution of the power and capacity and location of each energy storage device and consider the economic indicators of the system to solve the problem of new energy consumption has become a current research hotspot.

Literature [6] proposed a heat storage optimization configuration method for improving the level of intermittent energy consumption with the lowest operating cost and equipment cost as the optimization goal. There are also studies abroad that show that the configuration of electric boilers in the power system can improve the capacity of wind power ${ }^{[7]}$. Large-scale energy storage systems can stabilize wind power volatility and improve the power quality of wind power connected to the grid $^{[8]}$, while weakening the peak-to-valley contradiction between wind power, electrical load and thermal load ${ }^{[9]}$. Literature [10] configures the power and capacity of heat storage and electricity storage devices at the same time for the system with point-to-gas conversion, so that the system can achieve the economical optimum. However, this paper fails to consider the influence of the depth of discharge and the number of discharges on the life of the electricity storage device. Reference [11] uses the particle swarm algorithm to obtain the optimal configuration results of the energy storage device capacity and power when considering the life loss of the power storage device. Using the particle swarm algorithm to solve the bi-level programming problem has fast convergence speed and high efficiency. Simple advantages, but this article fails to consider the impact of different energy storage device configuration addresses on the system power flow. Moreover, the above research methods default to the fixed value of the configuration cost of energy storage unit 
power and capacity, which is inconsistent with the fact that the configuration cost will also change according to the land price of the energy storage location in practice.

In this paper, we study the above problems and propose an economical optimization configuration method for heat storage capacity and power, and capacity, power, and location of power storage devices. This method also considers the impact of the life of the power storage device along with the operation of the power storage device. And the impact of the configuration cost of the energy storage device with the change of the configuration location. The two-level programming model of the electric and heating integrated energy system is established, and the optimal configuration scheme is calculated by the particle swarm algorithm. Finally, through the simulation analysis of the IEEE classic 33-bus system, the effectiveness of the method is verified, and it has guiding significance for the configuration of various energy storage devices in the actual system.

\section{Changes of electric heating characteristics before and after heat storage devices in cogeneration units}

\subsection{Electric heating characteristics of the extraction steam unit without heat storage}

The correlation and coupling relationship between the generation power of the cogeneration unit $\left(\mathrm{p}_{\mathrm{el}}\right)$ and the external heating power $\left(\mathrm{p}_{\mathrm{h}}\right)$ is generally called the "electric heating characteristic", which can well reflect the external operating characteristics of the cogeneration unit, so it is an important part of the analysis of the flexible operation capability of the cogeneration unit. An effective way. Before configuring the heat storage device, the electrothermal characteristic diagram of the cogeneration unit is shown in Figure 1 below.

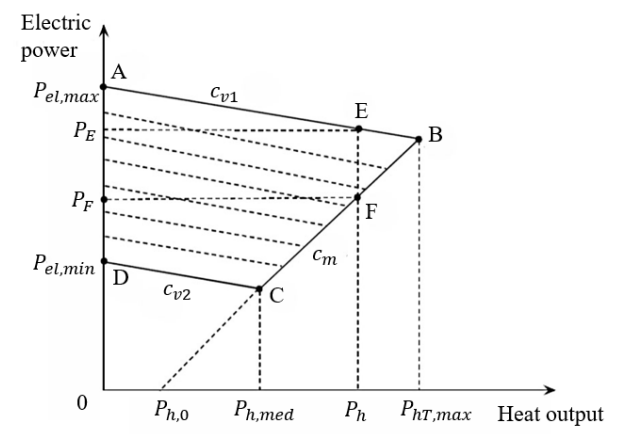

Figure 1. Electric heating characteristics of the extraction steam unit without heat storage

$\mathrm{c}_{\mathrm{v} 1}$ is the value of $\mathrm{c}_{\mathrm{v}}$ corresponding to the maximum electric output, $\mathrm{c}_{\mathrm{v} 2}$ is the value of $\mathrm{c}_{\mathrm{v}}$ corresponding to the minimum electric output, where $c_{v}$ is the reduction in power generation under the condition of the same amount of steam extracted and the unit heating heat is extracted; $c_{m}$ is the value of the back pressure operation The coefficient of elasticity of electric power and thermal power (that is, the slope of the back pressure curve, which can be approximated as a constant); $h_{0}$ is a constant;
$\mathrm{h}_{\mathrm{T}, \max }$ is the maximum heating power of the extraction steam unit; $h_{\text {med }}$ is the heat supply of the steam turbine when the generating power of the unit is minimum Power; $\mathrm{P}_{\max }$ and $\mathrm{p}_{\min }$ are the maximum and minimum power generation of the extraction steam generator under pure condensing conditions.

It can be seen from the operating interval shown in Figure 1 that under a given thermal load, the power generation has a certain degree of adjustability. For example, under the heating power $h$, the power generation can be adjusted between $\mathrm{P}_{\mathrm{E}}-\mathrm{P}_{\mathrm{F}}$, but The greater the thermal power, the smaller the adjustable range of the electrical power. This is because, under a given amount of steam extraction, this type of unit can adjust the electric power output of the entire steam turbine by adjusting the amount of steam for condensing power generation, but the larger the amount of extraction steam, the greater the proportion of steam that can be used for adjustment Less, so the adjustment range is smaller.

\subsection{Electric heating characteristics of the extraction steam unit with heat storage}

After the extraction steam generator is equipped with a thermal storage tank, its electric heating characteristics will also change. Suppose the design maximum heat storage and heat release power of the heat storage tank are $\mathrm{h}_{\mathrm{cmax}}$ and $\mathrm{h}_{\text {fmax }}$, respectively. For a certain power generation power, the heat is released through the heat storage tank, and the maximum heating power $\mathrm{h}$ of the whole (steam turbine and heat storage tank) will be on the original basis. Increase $\mathrm{h}_{\text {fmax }}$ upward, which is equivalent to that the $\mathrm{AB}$ and $\mathrm{BC}$ segments in Figure 1 are shifted to the right by $\mathrm{h}_{\text {fmax }}$ as a whole, as shown in Figure 2. In addition, when the power generation power of the steam turbine is between $p_{\min }-\mathrm{P}_{c}$ there is a minimum heating power (section CD in Figure 1). After the heat storage is configured, the minimum heating power will shift to the left by $\mathrm{h}_{\mathrm{cmax}}$. Therefore, as shown in Figure 2,the overall operating range of the extraction steam generator with heat storage is enclosed AGIJKLA.

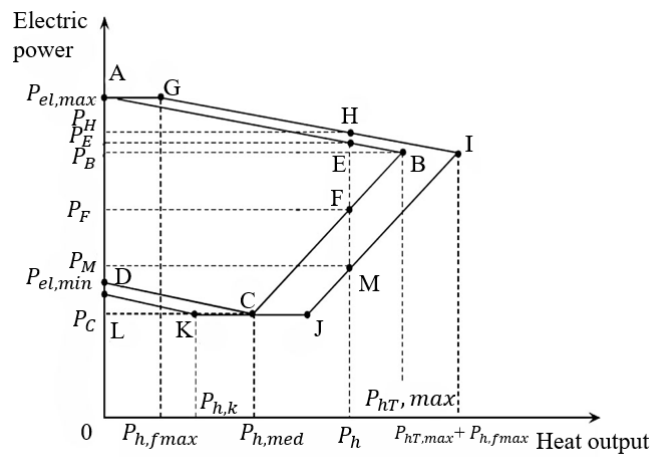

Figure 2. Electric heating characteristics of the extraction steam unit with heat storage

It can be seen that for a certain heating level $h$, before the heat storage is configured, the power generation of the cogeneration unit can only be adjusted between $\mathrm{P}_{\mathrm{E}}-\mathrm{P}_{\mathrm{F}}$ and after the heat storage is configured, the power generation of the steam turbine can be allowed to be between $\mathrm{P}_{\mathrm{M}}-\mathrm{P}_{\mathrm{H}}$. As a result, the insufficient heat supply of the steam 
turbine or the remaining part of the heat supply is compensated by heat storage to maintain the stability of the total heating power, thereby improving the peak regulation capacity of the cogeneration unit.

\section{Decision variables}

\subsection{Capacity and power of heat storage device}

From the principle of changing the peak-shaving capacity of the cogeneration unit by the heat storage device, it can be known that by increasing the power of the heat storage device, the original operating range translation range in the thermoelectric characteristic diagram becomes larger, so the operating range of the cogeneration unit becomes larger. The power generation power adjustment range of the steam turbine is allowed to be further increased. Therefore, the power change of the heat storage device will change the power output range of the cogeneration unit, thereby affecting the new energy consumption capacity of the system. If the capacity of the heat storage device is too small, the heat storage capacity of the heat storage device is limited, and the impact on the system is very small; if the capacity is too large, the heat storage will always be insufficient, and the capacity of the heat storage device is related to the initial investment of the heat storage device Cost is related and will cause waste. Therefore, it is necessary to optimize the capacity and power of the heat storage device to increase the system's new energy consumption when the investment cost is appropriate. Due to poor thermal conductivity, heat storage devices are generally directly configured in thermal power plants to adjust the thermoelectric characteristics of cogeneration units.

\subsection{Power storage device capacity, power and configuration location}

Configuring the storage device in the system can directly change the power output range of conventional thermal power units and cogeneration units through the charging and discharging of the storage device. By reasonably controlling the charging and discharging process of the storage device, it can provide space for the consumption of new energy. The increased power of the power storage device can store and release more electric energy in a short time, so the electric output adjustment range of the unit will increase accordingly, and the system will have a stronger ability to absorb new energy. Like the heat storage device, the energy storage device also needs an appropriate power storage capacity to function, so it is necessary to optimize the capacity and power of the power storage device. While optimizing the capacity and power of the power storage device, the configuration address of the power storage device will also have a certain impact. The electric energy conduction ability is strong, and the transmission is completed almost in an instant, which makes the configuration address of the power storage device very flexible. On the one hand, the configuration address of power storage will change the power flow of the entire system, and the change of configuration location may cause the power flowing through a branch to exceed its operating limit. On the other hand, the land price of different addresses will also significantly change the power storage. The initial investment cost of the device. So it is necessary to optimize the addressing of the storage device.

\section{Objective function}

\subsection{Upper-level planning objective function}

The objective function of the Upper-level planning is:

$$
\mathrm{F}=\sum T_{s i} C_{s, i}+\sum C_{h, i}+C_{q f}+C_{y}
$$

Among the formule, $T_{s i}$ is a variable of 0,1 , and 1 means that a power storage device is installed at node $i$, and 0 means that no power storage device is installed at node i. $\mathrm{C}_{\mathrm{s}, \mathrm{i}}, C_{h, i}$ are the initial investment costs of electricity and heat storage devices, $C_{q f}$ is the penalty cost of wind abandonment, and $C_{y}$ is the cost of the system during operation.

$\mathrm{C}_{\mathrm{S}, \mathrm{i}}$ can be obtained by the following formula:

$$
\begin{aligned}
\mathrm{C}_{\mathrm{s}, \mathrm{i}}=\left(K_{E, i} * S_{\max , i}+K_{P, i} * P_{s, i}\right) \\
* \frac{r_{0} *\left(1+r_{0}\right)^{Y_{S}}}{365 *\left[\left(1+r_{0}\right)^{Y_{S}}-1\right]}+\mathrm{K}_{\mathrm{W}} * \mathrm{P}_{\mathrm{s}, \mathrm{i}}
\end{aligned}
$$

Among the formula, $S_{\max , i}, P_{s, i}$ are the capacity and power of the power storage device at node i, respectively, and $K_{E, i}, K_{P, i}$ are the storage The cost coefficient of the capacity and power of the electric device at node i varies with the location of the node and is related to the land price of the node. $Y_{S}$ is the life of the storage device, and $r_{0}$ is the annual interest rate of the storage device. $\mathrm{K}_{\mathrm{W}}$ is the maintenance cost per day for each power storage.

$C_{h, i}$ can be obtained by the following formula

$$
\begin{aligned}
\mathrm{C}_{\mathrm{h}, \mathrm{i}}=\left(K_{e, i} * E_{h, i}\right. & \left.+K_{p, i} * P_{h, i}\right) * \frac{r_{1} *\left(1+r_{1}\right)^{Y_{h}}}{365 *\left[\left(1+r_{1}\right)^{\left.Y_{h}-1\right]}\right.} \\
& +\mathrm{K}_{\mathrm{w}} * \mathrm{P}_{\mathrm{h}, \mathrm{i}}
\end{aligned}
$$

Among the formula, from the working principle of the heat storage device, the heat storage device mainly works with the cogeneration unit, so the heat storage device is mainly configured in the thermal power plant. $E_{h, i}, P_{h, i}$ are the capacity and power of the thermal power plant configured at node $\mathrm{i}$ for the heat storage device, $K_{e, i}, K_{p, i}$ are the storage The cost coefficient of the capacity and power of the thermal device is related to the location of the thermal power plant. $Y_{h}$ is the life of the storage device, and $r_{1}$ is the annual interest rate of the storage device. $\mathrm{K}_{\mathrm{w}}$ is the daily maintenance cost of each power heat storage device.

$C_{q f}$ can be obtained by the following formula

$$
\mathrm{C}_{\mathrm{qf}}=K_{q f} *\left(P_{\text {for }}-P_{w}\right)
$$

Among the formula, $K_{q f}$ is the penalty factor corresponding to each unit of air curtailment, $P_{\text {for }}$ is the predicted value of system wind power output, and $P_{w}$ is the total output of wind power.

It represents the cost of coal consumption incurred during the operation of the units in the system, which 
mainly includes two parts: general thermal power units and cogeneration units.

$C_{y}$ represents the cost of coal consumption generated during the operation of the units in the system, which mainly includes two parts: general thermal power units and cogeneration units.

$$
C_{y}=\sum C_{c}(i, t)+\sum C_{e}(i, t)
$$

$C_{c}(i, t)$ is the cost of coal consumed by the thermal power unit at node $\mathrm{i}$ at time $\mathrm{t}$, and $C_{e}(i, t)$ is the cost of coal consumed by the cogeneration unit at node $\mathrm{i}$ at time t. $C_{c}(i, t)$ can be expressed as the quadratic function of electric output $p_{e l}^{t}$ at time t, $C_{e}(i, t)$ can be expressed as the quadratic function of electric output $p_{e l}^{t}$ and heat pawer $P_{h}^{t}$ at time t:

$$
C_{c}(i, t)=a_{i}\left(p_{e l, i}^{t}\right)^{2}+b_{i} p_{e l, i}^{t}+c_{i}
$$

$p_{e l, i}^{t}$ is the electric output of the thermal power unit at node $\mathrm{i}$ at time $\mathrm{t}$.

$$
\begin{gathered}
C_{e}(i, t)=A_{i}\left(p_{e l, i}^{t}\right)^{2}+B_{i} p_{e l, i}^{t}+C_{i} P_{h, i}^{t} P_{e l, i}^{t}+D_{i}\left(p_{h, i}^{t}\right)^{2} \\
+E_{i} p_{h, i}^{t}+F_{i}
\end{gathered}
$$

$p_{e l, i}^{t}$ is the electricity output of the cogeneration unit at node $\mathrm{i}$ at time $\mathrm{t}, p_{h, i}^{t}$ is the heat output of the cogeneration node $\mathrm{i}$ unit at time $\mathrm{t}$.

\subsection{Lower-level planning objective function}

The objective function of Lower-level planning is:

$$
\mathrm{F}=C_{q f}+C_{y}
$$

The lower-level planning is the operation planning of the entire system, and the objective function of the lowerlevel planning is the total cost of the system during operation, including the cost of abandonment penalty and the cost of coal consumption during the operation.

\section{Restrictions}

\subsection{Upper-level planning constraints}

The upper level planning is an unconstrained planning, which mainly gives the relationship between the initial investment cost and the decision variables.

\subsection{Lower-level planning constraints}

DC power flow constraints:

$$
\sum_{i} T_{j k}^{i}\left(P_{e l, i}^{t}+P_{w, i}^{t}+P_{d}^{t}-P_{c}^{t}\right)=P_{D, j k}^{t}
$$

Among the formula, $P_{w, i}^{t}$ is the wind power injection power of node i at time t, $P_{d}^{t}$ is the discharge power of the power storage device at time $\mathrm{t}, P_{c}^{t}$ is the charge power of the power storage device at time $t, T_{j k}^{i}$ is the transfer factor between the active power flow of branch $l_{j k}$ and the injected power of node $i$, and $P_{D, j k}^{t}$ is the active power of branch $l_{j k}$ at time $t$.

Upper limit constraint on active power of branch transmission:

$$
0 \leq P_{D, j k}^{t} \leq P_{j k, \max }
$$

Where $P_{j k, \max }$ is the upper limit of active power transmission of branch $l_{j \mathrm{k}}$.

Unit climbing rate constraint:

$$
P_{\text {ram }, i, \min } \leq P_{i}^{t}-P_{i}^{t-i} \leq P_{\text {ram }, i, \max }
$$

$P_{\text {ram,i,max }}$ is the upper limit of the thermal output of the unit at node i, $P_{\text {ram,i,min }}$ is the lower limit of the thermal output of the unit at node $i$.

Cogeneration unit output upper and lower limits:

$$
\begin{gathered}
\max \left\{c_{m, i} P_{h, i}^{t}+K_{i}, P_{e i, \min , i}-c_{v, i} P_{h, i}^{t}\right\} \leq P_{e l, i}^{t} \\
\leq P_{e l, \max , i}-c_{v, i} P_{h, i}^{t}
\end{gathered}
$$

$P_{e l, i}^{t}, \quad P_{h, i}^{t}$ are the electricity output and heat output of the cogeneration unit at node $\mathrm{i}$ at time $\mathrm{t}, P_{\text {ei,min }, i}$, $P_{e l, m a x, i}$ respectively represent the upper and lower limits of electric output under pure condensation conditions.

Heat storage and heat release power constraints:

$$
-\mathrm{P}_{\mathrm{h}} \leq S_{h, k}^{t}-S_{h, k}^{t-1} \leq P_{h}
$$

Capacity constraints of heat storage devices:

$$
\mathrm{S}_{\mathrm{h}, \mathrm{k}}^{\mathrm{t}} \leq \mathrm{E}_{\mathrm{h}}
$$

The battery energy storage model is as follows:

$$
\begin{gathered}
0 \leq \mathrm{P}_{\mathrm{C}} \leq \mathrm{P}_{\mathrm{s}} \\
0 \leq \mathrm{P}_{\mathrm{D}} \leq \mathrm{P}_{\mathrm{s}} \\
0 \leq \mathrm{SOC}_{\mathrm{t}} \leq \mathrm{E}_{\mathrm{s}} \\
\mathrm{SOC}_{\mathrm{t}+1}-\mathrm{SOC}_{\mathrm{t}}=\Delta \mathrm{t}\left(\mathrm{P}_{\mathrm{C}} \times \mathrm{k}_{\mathrm{C}}-\frac{\mathrm{P}_{\mathrm{D}}}{\mathrm{k}_{\mathrm{D}}}\right)
\end{gathered}
$$

$P_{C}, P_{D}, S O C, P_{\text {max }}, S_{\text {max }}, k_{C}, k_{D}$ are charging power, discharging power, storage power, maximum power, maximum power, charging efficiency, and discharging efficiency.

The heat storage remains unchanged before and after a cycle:

$$
\begin{aligned}
& \mathrm{S}_{\mathrm{h}, \mathrm{k}}^{0}=\mathrm{S}_{\mathrm{h}, \mathrm{k}}^{\mathrm{T}} \\
& \text { Maximum number of power storage devices: } \\
& 0 \leq T_{s i} \leq \mathrm{T}_{1}
\end{aligned}
$$

\section{Life loss model of power storage device}

This paper takes lithium batteries as the main research object. The working life of lithium batteries is a direct reflection of the capacity loss during the charge and discharge cycle. The factors affecting the battery working life include ambient temperature, peak charge current, depth of discharge, number of charge and discharge cycles, etc. Literature [12] have shown that the working life of a battery is closely related to its working mode. The depth of discharge is the most critical factor affecting the maximum number of cycles of the battery. The total electrical energy that can be released at a specific depth of discharge is certain, which is called effective discharge The total number of cycles of a lithium battery at a specific depth of discharge is constant. The greater the depth of discharge, the fewer the number of cycles of the battery and the shorter the working life of the corresponding battery. The relationship between the total number of cycles and the depth of charge and discharge of the lithium battery at the charge-discharge depth $d$ is as follows:

$$
\mathrm{N}_{\mathrm{d}}^{\text {fail }}=\mathrm{N}_{100}^{\text {fail }} \mathrm{d}^{-\mathrm{k}_{\mathrm{p}}}
$$


$\mathrm{N}_{100}^{\text {fail }}$ refers to the total number of charge and discharge times when the charge-discharge depth is $100 \%$, $\mathrm{k}_{\mathrm{p}}$ is the exponential coefficient of the cycle life of different types of energy storage batteries, and the value is generally provided by the battery manufacturer based on the experimental test results. For the charge-discharge cycle process of a certain discharge depth $\mathrm{d}$, it can be equivalent to the number of cycles at $100 \%$ chargedischarge depth. The conversion formula is as follows: $\mathrm{N}_{\mathrm{eq}}=\mathrm{D}_{\mathrm{d}} \mathrm{d}^{\mathrm{k}_{\mathrm{p}}}$

In the formula: $\mathrm{N}_{\mathrm{eq}}$ refers to the number of cycles equivalent to $100 \%$ charge and discharge depth, and $D_{d}$ is the number of cycles under charge and discharge depth $d$. According to the actual state of charge (soc) curve of the battery during the study period, the raindrop counting method is used to count and extract each actual cycle period and the corresponding discharge depth $\mathrm{d}$ in each cycle period.

\section{Typical day selection}

The typical day selection of the load curve in this paper is mainly divided into 8 categories. Since the load is quite different between the midweek and the weekend, it mainly includes the midweek and weekend of the four seasons of spring, summer, autumn and winter. The new energy power generation forecast value curve is divided into 4 categories, mainly The four seasons of spring, summer, autumn and winter are selected as the initial value of output. So there are 8 types of typical days in this article. Including the midweek and weekends under the four seasons of summer, autumn and winter, while considering the respective characteristics of the two types of curves.

\section{Algorithm flow for optimal configuration of electricity and heat storage devices}

This article mainly considers lithium batteries and thermal storage tanks as the main electricity and heat storage devices. The life of the lithium battery is affected by the depth of discharge of its work. It can be seen from the objective function expression that the initial investment cost of the battery varies with The change is caused by the change in battery life. The change is a change in the exponential relationship rather than a change in the linear relationship, which brings great trouble to the calculation. To address this issue, this article will adopt the battery life iteration method. The specific operation is to first give an initial battery life $\mathrm{Y}_{0}$. After the battery life is determined, the initial cost is only proportional to the capacity and power of the power storage device. Regularize the problem to obtain the soc curve of the power storage device to determine the battery life $Y_{S}$ under the initial life $\mathrm{Y}_{0}$. If the iteration condition is met, $\mathrm{Y}_{\mathrm{S}}$ is the actual life of the battery. If the condition is not met, $Y_{-} \mathrm{S}$ is taken as the new battery initial life $\mathrm{Y}_{0}$, Repeat the above steps to know the proper battery life Y. Regarding the life of the heat storage device, because the life of the heat storage device is relatively stable, it is generally directly regarded as an invariant. The specific configuration program steps are as follows:

Step 1. Use the K-means clustering algorithm to cluster the new energy output curves and daily load curves throughout the year, and obtain 8 types of typical wind power output curves and typical daily load curves in the four seasons of spring, summer, autumn and winter, as our planning Scene set.

Step 2. Set the initial life of the storage device $Y_{0}$.

Step 3. Use the particle swarm algorithm to solve the two-level programming problem to obtain the optimal configuration capacity and power of the electricity storage and heat storage device and the configuration location of the electricity storage device, and at the same time obtain the operating status of the electricity storage device through running simulation.

Step 4. Obtain the depth of discharge and the number of discharges of the power storage device by the raindrop counting method, so as to calculate the actual life $Y_{\mathrm{S}}$ of the power storage device under the initial life $Y_{0}$.

Step 5. Verify whether the life of the power storage device meets the error requirement $\left|\mathrm{Y}_{\mathrm{s}}-\mathrm{Y}_{0}\right|<1 \% \mathrm{Y}_{0}$. If the requirement is not met, set $Y_{S}$ as the initial life of the energy storage, and go back to step 2. If the requirements are met, $Y_{\mathrm{s}}$ is the battery life, and the result is the optimal configuration result.

In order to fully consider the uncertain characteristics of new energy power generation and the impact of energy storage life, the idea based on the combination of planning and operation and the output data of 96 points a day of new energy is adopted to solve the objective function by an improved particle swarm algorithm. The update formula of particle velocity and position in the iterative process of the improved particle swarm algorithm is:

$$
\begin{gathered}
v_{i d}^{t+1}=w v_{i d}^{t}+c_{1} r_{1}\left(P_{b i d}^{t}-x_{i d}^{t}\right)+c_{2} r_{2}\left(G_{d}^{t}-x_{i d}^{t}\right) \\
x_{i d}^{t+1}=x_{i d}^{t}+v_{i d}^{t+1} \\
w=w_{\text {max }}-\left(w_{\text {max }}-w_{\text {min }}\right) * \frac{t}{t_{\text {max }}}
\end{gathered}
$$

Where: $v_{i d}^{t}, x_{i d}^{t}$ are the velocity and position of particle $i$ in the dimension at time $t ; c_{1}, c_{2}$ are learning factors, which reflect the learning ability of each particle to two extreme values; $; r_{1}, r_{2}$ The value is a random number between $[0,1]$; $w$ is the weighting factor, $\mathrm{w}_{\max }$ is the upper limit of the weighting factor, $\mathrm{w}_{\min }$ is the lower limit of the weighting factor, and $t_{\max }$ is the maximum number of iterations; $t$ is the current number of iterations; $\mathrm{P}_{\text {bid }}^{\mathrm{t}}$ is the time $\mathrm{t}$ The best position that the particle $\mathrm{i}$ can find during the d-dimensional flight; $G_{d}^{t}$ is the best position that all particles can find during the $d$ dimensional flight at time $\mathrm{t}$.

\section{Case analysis}

This paper is based on the existing standard IEEE33 node power distribution demonstration system. The system wiring diagram is shown in Figure 3. Some improvements are made on the given parameters. Nodes 10 and 31 are connected to a $500 \mathrm{~kW}$ and $1000 \mathrm{~kW}$ wind farm respectively. The nodes 21 and 24 are respectively 
connected to a thermal power plant. In the calculation process, the charge/discharge efficiency of the energy storage system is $90 \%$; the initial capacity of the SOC is $20 \%$, the lower limit is $10 \%$, and the upper limit is $90 \%$; the annual interest rate of energy storage is $4.9 \%$, the annual maintenance cost coefficient, and $S_{\max }$ is in the process of solving The optimization range is set to $0 \sim$ $20 \% \times$ wind power installed capacity, the optimization step length is $5 \mathrm{MW}$, the $\mathrm{P} \_\mathrm{s}$ optimization range is set to battery type $0 \sim 200 \mathrm{MWh}$, the optimization step length is $5 \mathrm{MWh}$; the $E_{h}$ optimization range is set to $0 \sim 20 \% \times$ minimum heat treatment force, optimization step length is $5 \mathrm{MW}$, $P_{h}$ optimization range is set to $0 \sim 200 \mathrm{MWh}$, optimization step length is $5 \mathrm{MWh}$. The population size of the particle swarm in the optimization algorithm is 200 ; termination conditions: 1 . The evolutionary algebra reaches 100 generations; 2 . The objective function value changes less than 0.05 for 50 consecutive generations.

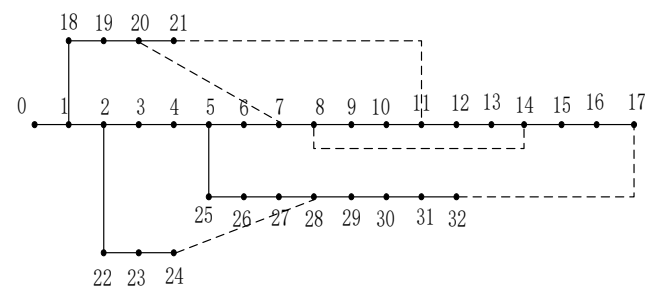

Figure 3: Standard IEEE33 node power distribution system

This paper clusters wind farm output scenes and analyzes the results of k-means clustering. The output curve of each typical scene obtained through clustering is shown in Figure 4. At the same time, the probability of each scene in a year is shown in Table 1.

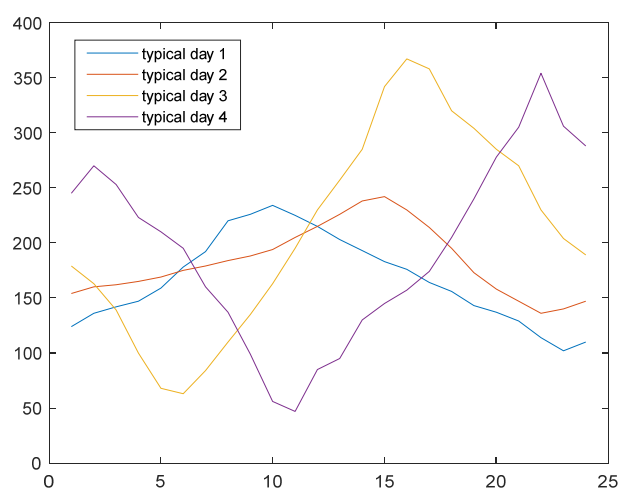

Figure 4: Clustering results of wind farm output scenarios

Table 1. Probability of typical scenarios in one year

\begin{tabular}{|c|c|}
\hline scenes & Probability \\
\hline Typical day 1 & $17.6 \%$ \\
\hline Typical day 2 & $28.5 \%$ \\
\hline Typical day 3 & $33.4 \%$ \\
\hline Typical day 4 & $21.5 \%$ \\
\hline
\end{tabular}

The optimal configuration scheme of energy storage obtained by the algorithm in this paper is: power storage device 1: capacity $80 \mathrm{MW}$, power $20 \mathrm{MWh}$, node 13 ; power storage device 2 : capacity $55 \mathrm{MW}$, power $15 \mathrm{MWh}$, node 18 ; heat storage device 1: 45MW, $15 \mathrm{MWh}$, node 21 . Heat storage device 2: 50MW, 20MWh, node 24;

Table 2. Simulation results

\begin{tabular}{|c|c|c|c|c|}
\hline & $\begin{array}{c}\text { witho } \\
\text { ut } \\
\text { energ } \\
\text { y } \\
\text { storag } \\
\text { e } \\
\end{array}$ & $\begin{array}{l}\text { with heat } \\
\text { storage }\end{array}$ & $\begin{array}{l}\text { with } \\
\text { power } \\
\text { storage }\end{array}$ & $\begin{array}{l}\text { Both with } \\
\text { power and } \\
\text { heat storage }\end{array}$ \\
\hline $\begin{array}{l}\text { wind } \\
\text { curtailm } \\
\text { ent rate }\end{array}$ & $11.4 \%$ & $5.3 \%$ & $4.3 \%$ & $2.5 \%$ \\
\hline $\begin{array}{c}\text { total } \\
\text { planning } \\
\text { and } \\
\text { operatio } \\
n \\
\text { cost/yua } \\
n \\
\end{array}$ & $\begin{array}{c}1.34^{*} \\
10^{8}\end{array}$ & $1.13 * 10^{8}$ & $1.30 * 10^{8}$ & $9.68 * 10^{7}$ \\
\hline $\begin{array}{c}\text { actual } \\
\text { life of } \\
\text { energy } \\
\text { storage/ } \\
\text { year }\end{array}$ & 0 & 0 & $\begin{array}{l}\text { power } \\
\text { storage1: } \\
10.24 \\
\text { power } \\
\text { storage2: } \\
12.21\end{array}$ & $\begin{array}{l}\text { power } \\
\text { storage 1: } \\
11.56 \\
\text { power } \\
\text { storage 2: } \\
13.42\end{array}$ \\
\hline
\end{tabular}

\section{Summary}

(1) In order to improve the capacity of new energy consumption, this paper proposes an algorithm for optimizing the configuration of the capacity and power of the electricity storage and heat storage devices at the same time as well as the configuration location. The simulation analysis of the actual project is carried out to verify This algorithm improves the effectiveness of wind power consumption.

(2) The algorithm fully considers that the life of the storage device is affected by the depth of discharge in the actual working process of the storage device, and uses an iterative algorithm to calculate the actual life of the storage device.

(3) Through the simulation example, it can be known that after adding the electricity storage and heat storage devices, the total cost of the system is reduced, and the wind power capacity of the system has been correspondingly improved.

\section{Acknowledgment}

This work is supported by the National Key Research and Development Program of China(2017YFB0902100).

\section{References}

1. Li Jianlin, Jin Wentao, Hui Dong, Zhang Yi. Typical applications and technology trends of large-scale energy storage in renewable energy power generation $[\mathrm{J}]$. Electrical Appliances and Energy Efficiency Management Technology, 2016(14): 9$14+61$. 
2. Guo Dan. Research on the high proportion of wind power connected to the grid to improve the absorption capacity [D]. Shenyang Agricultural University, 2017.

3. Li Hui. Research and application of power system planning considering large-scale new energy integration [D]. North China Electric Power University (Beijing), 2017.

4. Wang Xiaohai, Qiao Ying, Lu Zongxiang, et al. A new method for evaluating wind power consumption capacity during heating season[J]. Proceedings of the Chinese Society of Electrical Engineering, 2015, 35(9): 2112-2119.

5. Lu Quan, Chen Tianyou, Wang Haixia, Li Ling, Lu Yang, Li Weidong. Integrated electric and heating dispatching model for power system with heat storage [J]. Electric Power Automation Equipment, 2014, 34(05): 79-85.

6. Ge Weichun, Li Junhui, Ma Teng, Li Jiajue, Gao Kai, Yang Jinan, Wang Shunjiang. Optimal configuration of heat storage system capacity to improve wind power acceptance[J]. New Technology of Electrical Engineering and Energy, 2019, 39(04): 64-70.

7. Meibom P, Kiviluoma J, Barth R, et al. Value of electric heat boilers and heat pumps for wind power integration [J]. Wind Energy, 2007, 10(4): 321-337.

8. Zhou Rongzong. Research on Dispatching Strategy and Model of Active Load Participation in Renewable Energy Consumption[D]. Southeast University, 2016.

9. Yongfang,Jian,Quentin,Falcoz,Pierre,Neveu,Fengw u,Bai,Yan,Wang,Zhifeng Wang. Design and optimization of solid thermal energy storage modules for solar thermal power plant applications[J]. Applied Energy,2015, 139.

10. Zhao Dongmei, Xia Xuan, Tao Ran. Optimal configuration of combined heat and power microgrid electricity/heat integrated energy storage with electricity-to-gas conversion[J]. Automation of Electric Power Systems, 2019, 43(17): 46-61.

11. Wang Lei, Feng Bin, Wang Zhao, Fan Lixia, Yang Panfeng. Optimal configuration of wind and solar storage power station energy storage considering battery energy storage life loss[J]. Electric Power Science and Engineering, 2019, 35(05): 1- 6.

12. Zhou Huan. Research on key issues of source-load interaction in new energy power systems[D]. North China Electric Power University (Beijing), 2016. 